\title{
Dynamics of Network of Global Stock Markets
}

\author{
Xiao Fan Liu (Corresponding author) \\ Department of Electronic and Information Engineering \\ The Hong Kong Polytechnic University, Hong Kong \\ E-mail: xfliu@eie.polyu.edu.hk \\ Chi K. Tse \\ Department of Electronic and Information Engineering \\ The Hong Kong Polytechnic University, Hong Kong \\ E-mail: encktse@polyu.edu.hk
}

Received: March 20, 2012

Accepted: May 24, 2012

Online Published: June 5, 2012

doi:10.5430/afr.v1n2p1

URL: http://dx.doi.org/10.5430/afr.v1n2p1

\begin{abstract}
This paper studies the co-movement pattern of 67 stock market indices in the past 5 years. In order to capture the complex interaction of the stock markets, we propose a network approach to analyze the interdependence of the individual stock markets. Specifically, stock markets are considered as network nodes, and the network links (weights of links) are defined by the dynamic conditional correlation between market indices. We reveal the structure dynamics of global stock market integration by examining the variation of the network parameters as time elapses. We show that global stock markets have time-varying synchronization, and that developed markets tend to demonstrate stronger integration while emerging markets are statistically independent of each other. Furthermore, we show that stock markets of different countries generally behave in a synchronous manner when they experience fluctuation. This volatility spillover or financial contagion phenomenon is especially notable in the frontier markets. Our work exposes the interdependence of stock markets in the world and proposes a network approach to identifying some salient global behavior of the interconnecting markets.
\end{abstract}

Keywords: Complex network, Stock market, Network synchronization, Assortativity, Market integration, Volatility spillover, Financial contagion

\section{Introduction}

In the past two decades we have seen rapid globalization in the international financial market. Market integration, financial contagion, volatility spillover and market co-movement have been discussed extensively in the research literature since the 1970s. Hilliard (1979) provided an exposition of the relationship between equity indices on world exchange. Bekaert and Harvey (1995) measured capital market integration with a conditional regime-switching model. Bekaert et al. (2009); Baele and Inghelbrecht (2010); Fu and Pagani (2010); Wälti (2011) had described co-movements and integration of international stock markets with different mathematical models. Some researchers pointed out that an integrated capital market is required for individual as well as institutional investors to better allocate their portfolios in global markets (Palm et al. 2006). Other researchers also showed that globalization of financial markets had its pros and cons (Caporale et al., 2005; Greene et al., 2009). For example, Beine et al. (2010) argued that the increasing tail dependence emerged from global integration reduce the benefits of portfolio diversification. Hence, it is certainly of interest to study the overall structure of the global stock markets and how stock markets in different countries interact dynamically.

Researchers attempted to explain the structure of global stock markets in various ways. Roll (1992) compared stock price indices across 24 countries in an attempt to explain their disparate behaviors. Chan et al. (1997) studied long-term relationships among 18 national stock markets in 32 years. Bessler and Yang (2003) analyzed the dynamic structure of nine major stock markets using a directed acyclic graph approach. However, the methodologies used in these previous studies fall short of providing a convenient viewpoint for analyzing the interdependence of stock markets in different countries. To study the complex interdependence of the stock markets in the world, we introduce 
a new methodology which is capable of analyzing large interconnecting systems. Network theory has drawn great interest in physics research in the past decade and proved a powerful tool especially for analyzing large systems (Barabasi, 2009). Tse et al. (2010) applied the network approach to the analysis of stock market and revealed important statistical properties of the network of U.S. stocks. Gai and Kapadia (2010) analyzed contagion in financial networks. Atalay et al. (2011) characterized the buyer-supplier network of the US economy. Haldane (2009) provided insights on how network theory can be used to understand the financial contagion process and to investigate the stability of financial systems.

In Section 2 and Section 3, we construct a network of stock markets from 67 member countries of the World Federation of Exchanges. In the network, the nodes are the stock markets. Each pair of nodes are connected by an edge, assigned with a time-varying weight equal to the dynamic conditional correlation between the daily returns of the two adjacent markets indices. Our study considers the representative indices of each market from 2006 to 2010. We will examine the dynamics of the stock market network connectivity in Section 4 . Then in Section 5, we will investigate the relationships between network dynamics and some selected financial properties of the markets. In particular, synchronization is a special phenomenon that has been observed in many physical and man-made networks (Arenas et al., 2008), and we will make an attempt to demonstrate this universal behavior in the network of stock markets and to show how it is related to an important observed market behavior, namely, volatility.

\section{Network Construction}

A network is a collection of nodes connected by edges. In the network of global stock markets, each stock market is considered a node. Each pair of stock markets is connected by an edge, with its weight assigned by the dynamic conditional correlation (DCC) (Engle, 2002) between the daily logarithm return of the corresponding indices. Let $p_{i}(t)$ be the closing value of index $i$ on day $t$. The logarithm return $r_{i}(t+1)$ of index $i$ in the $(t+1)$ th day is given by

$$
r_{i}(t+1)=\ln \frac{p_{i}(t+1)}{p_{i}(t)}
$$

For each time $t$ the multivariate GARCH model gives a time-varying correlation $\rho_{i, j}(t)$ between stock markets $i$ and $j$. Hence a network of global stock markets with time-varying edge weights can be obtained. The following properties are particularly useful in characterizing the dynamics of the networks.

Definition 1 The node strength $s_{i}(t)$ of index $i$ on day $t$ is the average of the weights of all the edges connected to node $i$, i.e.,

$$
s_{i}(t)=\frac{1}{N-1} \sum_{j=1, i \neq j}^{N} \rho_{i, j}(t)
$$

where $N$ is the number of nodes. he node strength is a measure of the extent to which a particular stock market is correlated with other markets in the network.

Definition 2 Network synchronization $s_{N E T}(t)$ on day $t$ is the average of all the edge weights in the network, i.e.,

$$
s_{N E T}(t)=\frac{1}{N(N-1)} \sum_{i=1}^{N} \sum_{j=1, i \neq j}^{N} \rho_{i, j}(t)
$$

Taking a physical viewpoint, synchronization is a network phenomenon where the nodes (stock markets of different countries) tend to exhibit similar behavior.

Stock markets in the world can be grouped into different categories based on a number of criteria such as geometrical location, total capital or openness to foreign ownership, etc. A network is said to show assortative mixing if its nodes tend to connect tighter to other nodes with similar network properties (Newman, 2002). A generalized assortative mixing property can be used for examining the mesoscopic structure of the global stock market network. The definition of market assortativity is described as follows.

Definition 3 Market assortativity $r$. Let $P_{i}$ be the average value of the edge weights between node $i$ and other nodes in the same category as node $i$ and $Q_{i}$ be the average value of edge weightes between node $i$ and nodes in different categories as node $i$. If $P_{i}>Q_{i}$ then node $i$ has a preference for connecting itself with nodes within its 
own category and vice versa. The assortativity $r$ for a certain market category is defined by

$$
r(t)=\frac{\bar{P}_{i}(t)-\bar{Q}_{i}(t)}{2}
$$

where node $i$ is any stock market that belongs to this market category. The value of market assortativity $r$ ranges from -1 to 1 , where $r>0$ means that nodes have preference connecting to nodes within the same category and $r<0$ means that nodes have preference connecting to nodes in different categories.

\section{Data}

Our study considers stock markets from 67 member countries of the World Federation of Exchanges, including Argentina, Australia, Austria, Belgium, Brazil, Canada, Chile, China, Colombia, Czech republic, Denmark, Egypt, Finland, France, Germany, Greece, Hong Kong, Hungary, India, Indonesia, Ireland, Israel, Italy, Japan, Jordan, Korea, Malaysia, Mexico, Morocco, Netherlands, New Zealand, Norway, Pakistan, Peru, Philippines, Poland, Portugal, Russia, Singapore, South Africa, Spain, Sweden, Switzerland, Taiwan, Thailand, Turkey, United Kingdom, USA, Croatia, Estonia, Kenya, Lebanon, Mauritius, Nigeria, Slovenia, Sri Lanka, Tunisia, Bahrain, Bulgaria, Kuwait, Oman, Qatar, United Arab Emirates, Kazakhstan, Romania, Ukraine and Vietnam.

Daily closing values of MSCI Index (in USD) during the 818 working-day period from 1 December 2006 to 19 January 2010 are obtained for each of the 67 countries. In case a stock market is closed on a working-day, the day's closing value inherits from the last available day. All the data are provided by Morgan Stanley Capital Investment (MSCI) and retrieved from the MSCI Barra website (MSCI Barra, 2010a).

\section{Network Synchronization and Market Integration}

The global stock market network is constructed with time-varying edge weights. Figure 1 shows a snapshot of the network. With all edges included, the number of nodes and edges in the constructed network are 67 and 2211, respectively. Figure 2 shows the distribution of all time-varying edge weights. It can be seen that majority of the time-varying correlations fall between 0 and 0.5 , with a small portion being larger than 0.5 and a few smaller than 0 .

The network synchronization describes how closely the stock markets of different countries are integrating. Figure 3(a) shows the network synchronization over time. We can observe that the network generally maintains a synchronization value at around 0.3 . It is worth noting that the network shows a periodic behavior. Before January 2009 , for every half a year the synchronization suddenly reached a peak and slowly dropped to a lower value (circled in Figure 3(a)). While after the financial crisis in 2008, the synchronization of the global stock market stabilized at a slightly higher value than before the crisis. The node strength, to a smaller scale, describes the connectivity of a node to its peer nodes. Figure 3(b) shows the node strengths of Hong Kong and United States stock markets. In the individual cases the connectivity of each node exhibited different behavior and the periodic rise and drop behavior of node strength was not as obvious as it is in the synchronization of network. The force driving the time-varying node strength, periodic network synchronization behavior and the stabilization of the synchronization after financial crisis is an open question to researchers. One of the feasible methodology could be the generalized method of moments (GMM) estimators (Ahn and Pérez, 2010) which shows that international stock returns are indeed influenced by some strong global factor.

The 67 stock markets investigated in this paper can be classified into three categories, namely, developed, emerging and frontier markets according to the MSCI's Index Country Membership classification (MSCI Barra, 2010b), as shown in Table 1. The stock markets can also be naturally categorized by the continents they are in, i.e., European, American, Asian and Africa/Middle East. Here we calculate the assortative mixing of the stock markets in each category using the generalized market assortativity defined in Eqn. (4). Figure 4 shows the time-varying assortativity of the stock markets grouped by different criteria. It is found that developed markets tend to have higher correlation within the same group than those in different groups, whereas no obvious conclusion can be drawn to the countries in the frontier and emerging markets. Similarly, it can also be seen that European markets exhibit higher assortativity than markets on other continents.

Figures 5 to 8 show the snapshots of the network during the periodic synchronization. We can find that when the global stock market network is weakly synchronized, developed markets tend to form a tight cluster while emerging and frontier markets are loosely connected in the system. During strong synchronization of global stock market network, developed market and some emerging markets form a tight cluster while more emerging and frontier markets joined the largest cluster of the network. The categorization of developed, emerging and frontier markets is largely based on several market accessibility criteria such as openness to foreign ownership, ease of capital 
inflows/outflows and efficiency of the operational framework. Considering European markets are mostly developed markets, our finding in the assortative mixing pattern in the network shows that the global market behavior will have a relatively stronger domino effect within the developed markets which are more open to foreign investors than those less developed markets. Haldane (2009); Beine et al. (2010) argued that the integration of global stock markets decreases the market diversification hence increases portfolio risks. The strong assortative integration phenomena we observed in European and developed markets may indicate reduced benefits of portfolio diversification of investments in these countries.

\section{Network Dynamics and Volatility Spillover}

In this section we will study the relationship between network dynamics and stock market dynamics. In particular, we consider the time-varying index closing values, return and volatility for each individual stock market.

We take the MSCI World Index (MSCI Barra, 2010b) as the stock market index of the global stock market system (Note 1). The dynamics of the closing value, logarithm return and volatility of the World Index (shown in Figure 9) are indicative of how the global financial system behaves. First, we compare the network synchronization with the dynamics of the World Index. Specifically, the correlations between network synchronization, World Index closing values, logarithm return and volatility are calculated using Pearson's correlation coefficient. For example, the correlation coefficient $\rho_{s, r}$ between network synchronization $s$ and World Index return $r$ is given by

$$
\rho_{s, r}=\frac{\operatorname{cov}(s, r)}{\sigma_{s} \sigma_{r}}
$$

A graphical representation of the relationships among the network and stock market dynamics is shown in Figure 10. It can be found that the network synchronization and World Index volatility are strongly correlated with correlation coefficients 0.72 , comparing to those between other pairs of dynamical properties. It is also worth noting that the correlation between network synchronization and World Index closing value are negatively correlated with correlation coefficients -0.64 . The network synchronization is actually an assembly of all the individual node strengths. It is also of interest to know whether the market dynamics of individual stocks are also related to their network connectivity. The volatilities of each stock market index are measured by the univariate GARCH model (Bollerslev, 1986). It can be found in Table 2 that markets whose node strengths are highly positive or negative correlated to the index volatility are mostly frontier markets, while the correlations are much smaller for developed markets.

The relationship between volatility and co-movement of markets has been extensively reported in the literature. Hamao et al. (1990); King et al. (1994); Susmel and Engle (1994); Theodossiou et al. (1997); Longin and Solnik (2001); Ramchand and Susmel (1998); Allen and Gale, 2000; Forbes and Rigobon, 2000; Ng (2000); Claessens and Forbes, 2001; Baele (2005); Diebold and Yilmaz (2009) examined volatility spillover from across individual markets to across markets in multiple regions. Using the data from 67 stock markets during 2006 to 2009, we showed in a systematic way that the global stock markets generally demonstrate a positive correlation between volatility and integration. Our analysis also shows that the volatility spillover or sometimes called financial contagion is less severe in developed markets than in other markets. Emerging and frontier markets demonstrate sensitive behavior of integration into the global stock market system when their markets fluctuate. In light of this result, policy makers, especially those from countries of emerging markets, have to be fully aware of the impact of the globally integrated financial market before opening up their own to foreign investors.

\section{Conclusion}

A network of stock markets from 67 countries has been constructed by connecting each pair of stock markets according to the dynamic conditional correlations between their representative indices. We have studied the dynamics of the network connectivity during the period from 1 December 2006 to 19 January 2010. Taking a systematic approach, we have first shown that the degree of integration of international financial market varies with time. Specifically the network exhibited periodic synchronization behavior before the 2008 financial crisis and after the crisis the network stayed stabilized in a slightly higher state. Furthermore, developed markets tended to connect more closely with each other, while frontier and emerging markets integrated into global stock market system in a timely fashion. By studying the relationship of network properties such as synchronization and node strengths with the market properties such as value, return and volatility, we discovered that stock markets generally behave in a synchronous manner when they experience fluctuation. However, this volatility spillover or financial contagion phenomenon affects frontier markets more than developed markets. 
We have demonstrated in this paper that the network approach is a viable methodology for probing into the behavior of global markets as a complex interconnecting system. Comparing to previous research, the network approach has proven to be more systematic and effective. We believe that the application of network theory in financial study would provide an effective approach to identifying the interdependence of individual markets and would likely provide quantitative descriptions of some important systematic phenomena in finance.

\section{References}

Ahn, S. C., \& Pérez, M. F. (2010). GMM estimation of the number of latent factors: With application to international stock markets. Journal of Empirical Finance, 17(4), 783-802. http://dx.doi.org/10.1016/j.jempfin.2010.04.005

Allen, F., \& Gale, D. (2000). Financial contagion. Journal of Political Economy, 108(1), 1-33. http://dx.doi.org $/ 10.1086 / 262109$

Arenas, A., Díaz-Guilera, A., Kurths, J., Moreno, Y., \& Zhou, C. (2008). Synchronization in complex networks. Physics Reports, 469(3), 93-153. http://dx.doi.org/10.1016/j.physrep.2008.09.002

Atalay, E., Hortaçsu, A., Roberts, J., \& Syverson, C. (2011). Network structure of production. Proceedings of the National Academy of Sciences, 108(13), 5199-5202. http://dx.doi.org/10.1073/pnas.1015564108

Baele, L. (2005). Volatility Spillover Effects in European Equity Markets. Journal of Financial and Quantitative Analysis, 40(02), 373-401. http://dx.doi.org/10.1017/S0022109000002350

Baele, L., \& Inghelbrecht, K. (2010). Time-varying integration, interdependence and contagion. Journal of International Money and Finance, 29(5), 791-818. http://dx.doi.org/10.1016/j.jimonfin.2009.12.008

Barabási, A.-L. (2009). Scale-Free Networks: A Decade and Beyond. Science, 325(5939), 412-413. http://dx.doi.org/10.1126/science.1173299

Beine, M., Cosma, A., \& Vermeulen, R. (2010). The dark side of global integration: Increasing tail dependence. Journal of Banking \& Finance, 34(1), 184-192. http://dx.doi.org/10.1016/j.jbankfin.2009.07.014

Bekaert, G., \& Harvey, C. R. (1995). Time-Varying World Market Integration. The Journal of Finance, 50(2), 403-444.

Bekaert, G., Hodrick, R. J., \& Zhang, X. (2009). International Stock Return Comovements. The Journal of Finance, 64(6), 2591-2626. http://dx.doi.org/10.1111/j.1540-6261.2009.01512.x

Bessler, D. A., \& Yang, J. (2003). The structure of interdependence in international stock markets. Journal of International Money and Finance, 22(2), 261-287. http://dx.doi.org/10.1016/s0261-5606(02)00076-1

Bollerslev, T. (1986). Generalized autoregressive conditional heteroskedasticity. Journal of Econometrics, 31(3), 307-327. http://dx.doi.org/10.1016/0304-4076(86)90063-1

Caporale, G. M., Cipollini, A., \& Spagnolo, N. (2005). Testing for contagion: a conditional correlation analysis. Journal of Empirical Finance, 12(3), 476-489. http://dx.doi.org/10.1016/j.jempfin.2004.02.005

Chan, K. C., Gup, B. E., \& Pan, M.-S. (1997). International Stock Market Efficiency and Integration: A Study of Eighteen Nations. Journal of Business Finance \& Accounting, 24(6), 803-813. http://dx.doi.org/10.1111/1468-5957.00134

Claessens, S., \& Forbes, K. (2001). International financial contagion: Springer Netherlands.

Diebold, F. X., \& Yilmaz, K. (2009). Measuring Financial Asset Return and Volatility Spillovers, with Application to Global Equity Markets. The Economic Journal, 119(534), 158-171. http://dx.doi.org/10.1111/j.1468-0297.2008.02208.x

Engle, R. (2002). Dynamic Conditional Correlation. Journal of Business and Economic Statistics, 20(3), 339-350. http://dx.doi.org/10.1198/073500102288618487

Forbes, K., \& Rigobon, R. (2000). Contagion in Latin America: Definitions, Measurement, and Policy Implications. National Bureau of Economic Research Working Paper Series, No. 7885.

$\mathrm{Fu}, \mathrm{R}$., \& Pagani, M. (2010). On the cointegration of international stock indices. Journal of Economics and Finance, 1-18. http://dx.doi.org/10.1007/s12197-010-9136-9

Gai, P., \& Kapadia, S. (2010). Contagion in financial networks. Proceedings of the Royal Society A: Mathematical, Physical and Engineering Science, 466(2120), 2401-2423. http://dx.doi.org /10.1098/rspa.2009.0410 
Greene, W. H., Hornstein, A. S., \& White, L. J. (2009). Multinationals do it better: Evidence on the efficiency of corporations' capital budgeting. Journal of Empirical Finance, 16(5), 703-720. http://dx.doi.org/10.1016/j.jempfin.2009.07.004

Haldane, A. (2009). Rethinking the financial network. Speech at Financial Student Association, Amsterdam, April.

Hamao, Y., Masulis, R., \& Ng, V. (1990). Correlations in price changes and volatility across international stock markets. Review of Financial Studies, 3(2), 281-307. http://dx.doi.org/10.1093/rfs/3.2.281

Hilliard, J. E. (1979). The Relationship Between Equity Indices on World Exchanges. The Journal of Finance, 34(1), 103-114.

King, M., Sentana, E., \& Wadhwani, S. (1994). Volatility and Links between National Stock Markets. Econometrica, 62(4), 901-933.

Longin, F., \& Solnik, B. (2001). Extreme Correlation of International Equity Markets. The Journal of Finance, 56(2), 649-676. http://dx.doi.org/10.1111/0022-1082.00340

MSCI Barra (Accessed on November 30, 2010a). MSCI Market Classification Framework. http://www.mscibarra.com/products/indices/international_equity_indices/market_classification.html.

MSCI Barra (Accessed on November 30, 2010b). Index Definitions. http://www.mscibarra.com/products/indices/international_equity_indices/definitions.html\#WORLD.

Newman, M. E. J. (2002). Assortative mixing in networks. Physical Review Letters, 89(20), 208701. http://dx.doi.org/10.1103/Physrevlett.89.208701

$\mathrm{Ng}$, A. (2000). Volatility spillover effects from Japan and the US to the Pacific-Basin. Journal of International Money and Finance, 19(2), 207-233. http://dx.doi.org/10.1016/s0261-5606(00)00006-1

Palm, F. C., Werner, I. M., \& Wolff, C. C. P. (2006). Introduction to the special issue on International Finance. Journal of Empirical Finance, 13(4-5), 393-395. http://dx.doi.org/10.1016/j.jempfin.2006.05.001

Ramchand, L., \& Susmel, R. (1998). Volatility and cross correlation across major stock markets. Journal of Empirical Finance, 5(4), 397-416. http://dx.doi.org/10.1016/s0927-5398(98)00003-6

Roll, R. (1992). Industrial structure and the comparative behavior of international stock market indices. Journal of Finance, 3-41.

Wälti, S. (2011). Stock market synchronization and monetary integration. Journal of International Money and Finance, 30(1), 96-110. http://dx.doi.org/10.1016/j.jimonfin.2010.07.004

Susmel, R., \& Engle, R. F. (1994). Hourly volatility spillovers between international equity markets. Journal of International Money and Finance, 13(1), 3-25. http://dx.doi.org/10.1016/0261-5606(94)90021-3

Theodossiou, P., Kahya, E., Koutmos, G., \& Christofi, A. (1997). Volatility Reversion and Correlation Structure of Returns in Major International Stock Markets. Financial Review, 32(2), 205-224. http://dx.doi.org/10.1111/j.1540-6288.1997.tb00422.x

Tse, C. K., Liu, J., \& Lau, F. C. M. (2010). A network perspective of the stock market. Journal of Empirical Finance, 17(4), 659-667. http://dx.doi.org/10.1016/j.jempfin.2010.04.008

\section{Notes}

Note 1. As of June 2007 the MSCI World Index was consisted of the following 23 Developed Market country indices: Australia, Austria, Belgium, Canada, Denmark, Finland, France, Germany, Greece, Hong Kong, Ireland, Italy, Japan, Netherlands, New Zealand, Norway, Portugal, Singapore, Spain, Sweden, Switzerland, the United Kingdom, and the United States. 
Table 1. MSCI's Index Country Membership

\begin{tabular}{|l|l|}
\hline \multicolumn{1}{|c|}{ Categorization } & Countries \\
\hline Developed markets & $\begin{array}{l}\text { Australia, Austria, Belgium, Canada, Denmark, Finland, France, Germany, } \\
\text { Greece, Hong Kong, Ireland, Italy, Japan, Netherlands, New Zealand, Norway, } \\
\text { Portugal, Singapore, Spain, Sweden, Switzerland, UK, USA. }\end{array}$ \\
\hline Emerging markets & $\begin{array}{l}\text { Brazil, Chile, China, Colombia, Czech Republic, Egypt, Hungary, India, } \\
\text { Indonesia, Israel, Korea, Malaysia, Mexico, Morocco, Peru, Philippines, Poland, } \\
\text { Russia, South Africa, Taiwan, Thailand, Turkey. }\end{array}$ \\
\hline Frontier markets & $\begin{array}{l}\text { Argentina, Bahrain, Bulgaria, Croatia, Estonia, Jordan, Jamaica, Kazakhstan, } \\
\text { Kenya, Kuwait, Lebanon, Mauritius, Nigeria, Oman, Pakistan, Qatar, Romania, } \\
\text { Slovenia, Sri Lanka, Tunisia, Ukraine, UAE, Vietnam. }\end{array}$ \\
\hline
\end{tabular}

MSCI's Index Country Membership categorizes the countries into developed, emerging and frontier markets.

Table 2. Pearson's correlation coefficients between each pair of node strength $i$, index volatility $\sigma$, logarithm return $r$ and closing prices $p$ for each node

\begin{tabular}{|l|l|l|c|c|c|}
\hline Country & Classification & Continent & $\rho_{s, \sigma}$ & $\rho_{s, r}$ & $\rho_{s, p}$ \\
\hline QATAR & Frontier & Africa/Middle East & 0.31 & 0.11 & -0.03 \\
\hline JORDAN & Frontier & Africa/Middle East & 0.26 & -0.06 & -0.17 \\
\hline KUWAIT & Frontier & Africa/Middle East & 0.20 & 0.16 & -0.07 \\
\hline KAZAKHSTAN & Frontier & Asia/Pacific & 0.20 & -0.05 & 0.19 \\
\hline OMAN & Frontier & Africa/Middle East & 0.20 & -0.01 & -0.31 \\
\hline UAE & Frontier & Africa/Middle East & 0.19 & 0.18 & -0.09 \\
\hline EGYPT & Emerging & Africa/Middle East & 0.17 & 0.25 & -0.01 \\
\hline PAKISTAN & Frontier & Asia/Pacific & 0.17 & -0.10 & -0.14 \\
\hline KOREA & Emerging & Asia/Pacific & 0.15 & -0.05 & 0.32 \\
\hline PERU & Emerging & Americas & 0.14 & -0.16 & -0.06 \\
\hline IRELAND & Developed & Europe & 0.14 & 0.03 & 0.23 \\
\hline PORTUGAL & Developed & Europe & 0.13 & 0.05 & -0.10 \\
\hline MOROCCO & Emerging & Africa/Middle East & 0.13 & 0.00 & -0.15 \\
\hline SWEDEN & Developed & Europe & 0.12 & -0.14 & -0.04 \\
\hline ROMANIA & Frontier & Europe & 0.11 & -0.10 & -0.13 \\
\hline THAILAND & Emerging & Asia/Pacific & 0.11 & -0.07 & 0.09 \\
\hline USA & Developed & Americas & 0.11 & -0.15 & -0.07 \\
\hline BAHRAIN & Frontier & Asia/Pacific & 0.10 & 0.20 & 0.06 \\
\hline NEW ZEALAND & Developed & Asia/Pacific & 0.09 & 0.01 & -0.03 \\
\hline HUNGARY & Emerging & Europe & 0.08 & -0.09 & 0.26 \\
\hline DENMARK & Developed & Europe & 0.07 & -0.03 & 0.00 \\
\hline ISRAEL & Emerging & Africa/Middle East & 0.07 & -0.16 & -0.09 \\
\hline NETHERLANDS & Developed & Europe & 0.07 & 0.04 & -0.02 \\
\hline CANADA & Developed & Americas & 0.06 & -0.09 & 0.20 \\
\hline FRANCE & Developed & Europe & 0.06 & -0.06 & 0.06 \\
\hline ITALY & Developed & Europe & 0.06 & -0.02 & 0.11 \\
\hline LEBANON & Frontier & Africa/Middle East & 0.06 & -0.03 & 0.02 \\
\hline & & & & 0.06 \\
\hline
\end{tabular}




\begin{tabular}{|c|c|c|c|c|c|}
\hline SINGAPORE & Developed & Asia/Pacific & 0.06 & -0.13 & -0.08 \\
\hline GERMANY & Developed & Europe & 0.04 & -0.04 & 0.00 \\
\hline VIETNAM & Frontier & Asia/Pacific & 0.03 & 0.27 & -0.21 \\
\hline KENYA & Frontier & Africa/Middle East & 0.03 & 0.13 & -0.10 \\
\hline INDIA & Emerging & Asia/Pacific & 0.02 & -0.09 & 0.00 \\
\hline BELGIUM & Developed & Europe & 0.02 & 0.00 & 0.05 \\
\hline GREECE & Developed & Europe & 0.01 & -0.13 & -0.17 \\
\hline TAIWAN & Emerging & Asia/Pacific & 0.01 & 0.02 & 0.12 \\
\hline NORWAY & Developed & Europe & 0.01 & -0.24 & 0.00 \\
\hline AUSTRIA & Developed & Europe & 0.00 & -0.10 & 0.12 \\
\hline CROATIA & Frontier & Europe & -0.01 & -0.06 & 0.04 \\
\hline SPAIN & Developed & Europe & -0.01 & -0.06 & 0.10 \\
\hline ESTONIA & Frontier & Europe & -0.01 & -0.02 & -0.13 \\
\hline SWITZERLAND & Developed & Europe & -0.01 & -0.17 & -0.08 \\
\hline HONG KONG & Developed & Asia/Pacific & -0.01 & 0.02 & -0.12 \\
\hline UNITED KINGDOM & Developed & Europe & -0.02 & -0.18 & 0.00 \\
\hline CZECH REPUBLIC & Emerging & Europe & -0.02 & -0.14 & 0.18 \\
\hline FINLAND & Developed & Europe & -0.02 & -0.05 & 0.03 \\
\hline TURKEY & Emerging & Europe & -0.03 & -0.34 & -0.07 \\
\hline NIGERIA & Frontier & Africa/Middle East & -0.04 & -0.08 & -0.16 \\
\hline BRAZIL & Emerging & Americas & -0.05 & -0.09 & 0.12 \\
\hline POLAND & Emerging & Europe & -0.05 & -0.20 & 0.01 \\
\hline INDONESIA & Emerging & Asia/Pacific & -0.06 & 0.03 & 0.33 \\
\hline JAPAN & Developed & Asia/Pacific & -0.06 & 0.00 & -0.02 \\
\hline CHILE & Emerging & Americas & -0.06 & -0.21 & -0.01 \\
\hline MEXICO & Emerging & Americas & -0.07 & -0.16 & 0.03 \\
\hline RUSSIA & Emerging & Europe & -0.08 & -0.09 & 0.34 \\
\hline CHINA & Emerging & Asia/Pacific & -0.09 & 0.09 & 0.04 \\
\hline BULGARIA & Frontier & Europe & -0.09 & 0.08 & -0.17 \\
\hline SOUTH AFRICA & Emerging & Africa/Middle East & -0.10 & -0.16 & -0.02 \\
\hline MALAYSIA & Emerging & Asia/Pacific & -0.11 & 0.04 & -0.09 \\
\hline AUSTRALIA & Developed & Asia/Pacific & -0.11 & -0.04 & 0.00 \\
\hline PHILIPPINES & Emerging & Asia/Pacific & -0.19 & 0.05 & -0.08 \\
\hline MAURITIUS & Frontier & Asia/Pacific & -0.20 & 0.22 & -0.26 \\
\hline SRI LANKA & Frontier & Asia/Pacific & -0.20 & -0.06 & -0.22 \\
\hline TUNISIA & Frontier & Africa/Middle East & -0.21 & -0.15 & -0.22 \\
\hline ARGENTINA & Frontier & Americas & -0.25 & -0.08 & 0.12 \\
\hline UKRAINE & Frontier & Europe & -0.25 & -0.29 & -0.28 \\
\hline SLOVENIA & Frontier & Europe & -0.26 & 0.09 & -0.17 \\
\hline COLOMBIA & Emerging & Americas & -0.29 & -0.19 & 0.17 \\
\hline
\end{tabular}

The table is sorted by $\rho_{s, \sigma}$ between node strength $s$ and index volatility $\sigma$. 


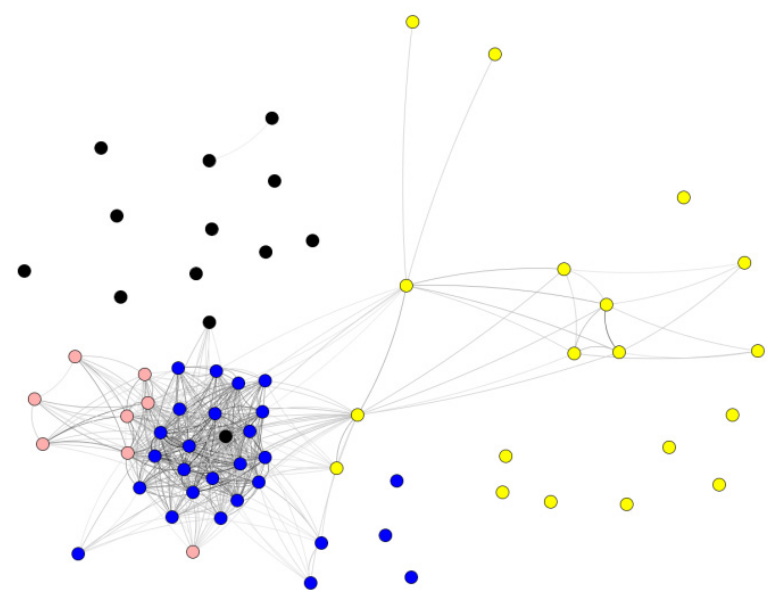

Figure 1. A snapshot of the network of global stock market network (on Day 600). For clarity of presentation of the network, edges with weights below 0.5 are not shown. Yellow nodes represent stock market indices from the Asia Pacific region; red from the Americas; blue from Europe; and black from the Africa/Middle East region. Note that all the American markets and most of the European markets are connected while half of the Asian markets and most of the African/Middle East markets are isolated on this day.

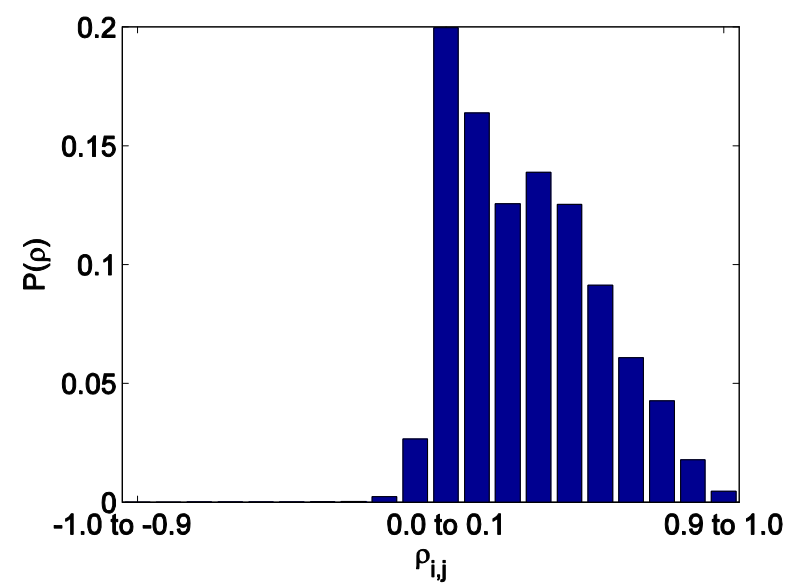

Figure 2. Distribution of time-varying edge weights. $\rho_{i, j}$ is the weight of edge connecting each pair of nodes and $P(\rho)$ is the probability of an edge weight falling in a 0.1 interval.

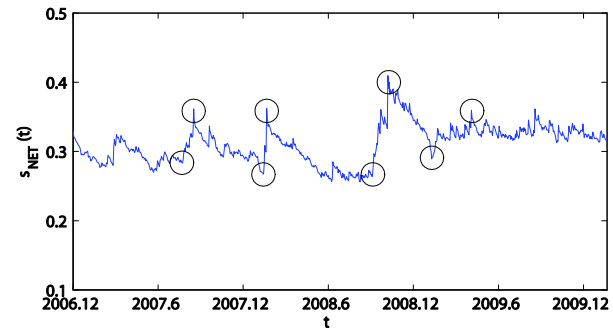

(a)

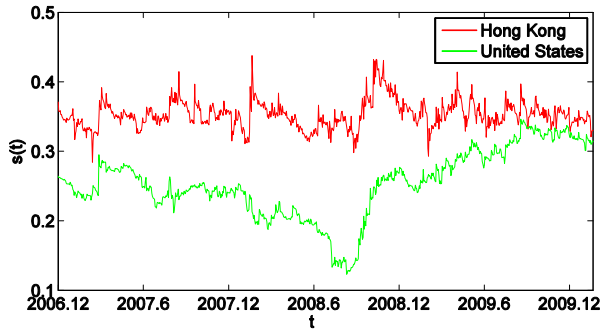

(b)

Figure 3. (a) Network synchronization. Circles are drawn to indicate periodic behavior of network synchronization. (b) Node strength of Hong Kong stock market (red) and United States stock market (green). 


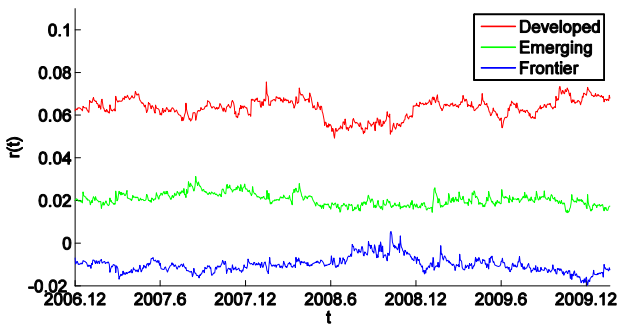

(a)

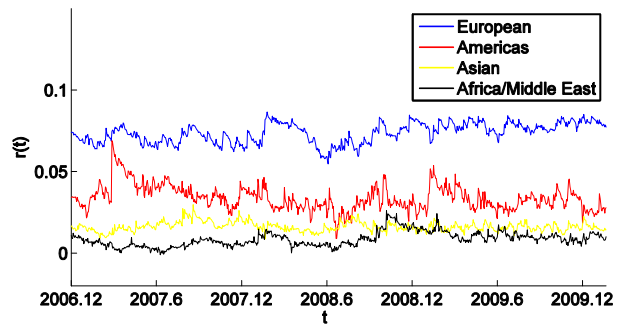

(b)

Figure 4. Dynamics of assortativity of nodes in different categories. (a) Markets categorized by MSCI's Index Country Membership classification. (b) Markets categorized by geometric location.

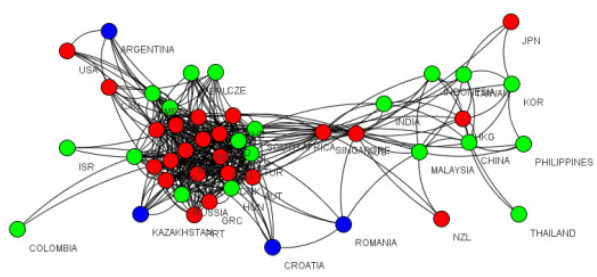

Day 168

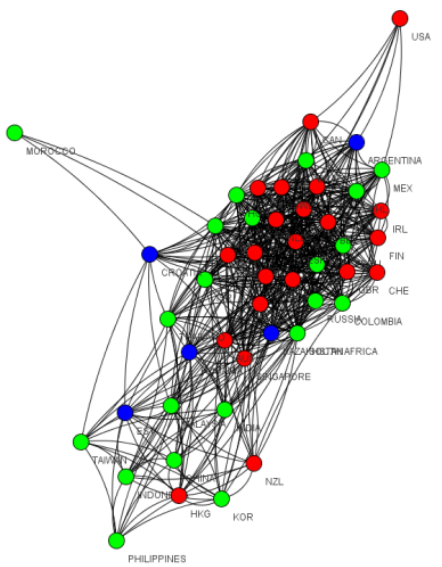

Day 185

Figure 5. Snapshots of global stock market network in Day 168 and Day 185, during the first synchronized period. Developed markets are marked as red, emerging markets green and frontier markets blue. Network edges with weight less than 0.5 are eliminated as well as nodes with no edges with weight no less than 0.5.

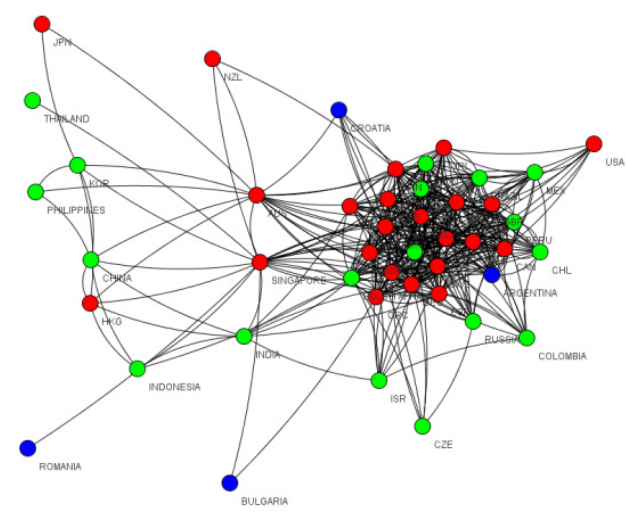

Day 292

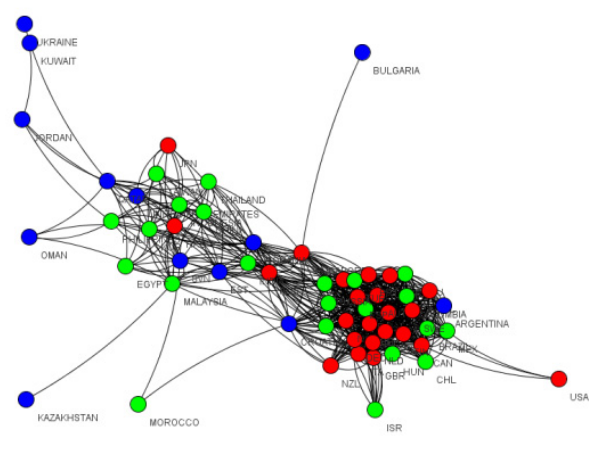

Day 297

Figure 6. Snapshots of global stock market network in Day 292 and Day 297, during the second synchronized period.

Developed markets are marked as red, emerging markets green and frontier markets blue. Network edges with weight less than 0.5 are eliminated as well as nodes with no edges with weight no less than 0.5 . 


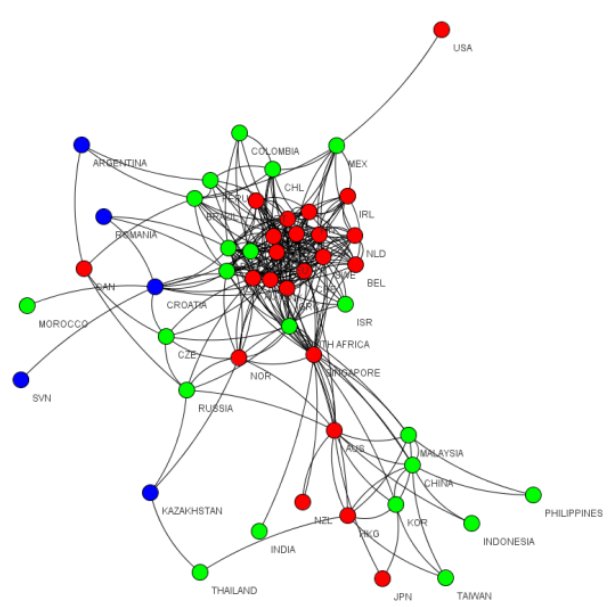

Day 440

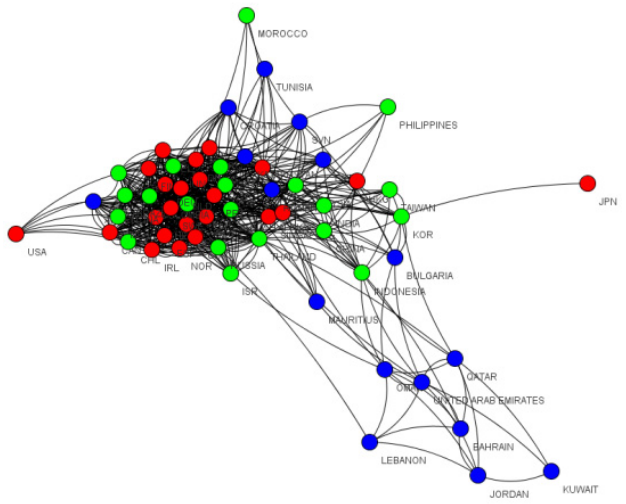

Day 482

Figure 7. Snapshots of global stock market network in Day 440 and Day 482, during the third synchronized period. Developed markets are marked as red, emerging markets green and frontier markets blue. Network edges with weight less than 0.5 are eliminated as well as nodes with no edges with weight no less than 0.5 .

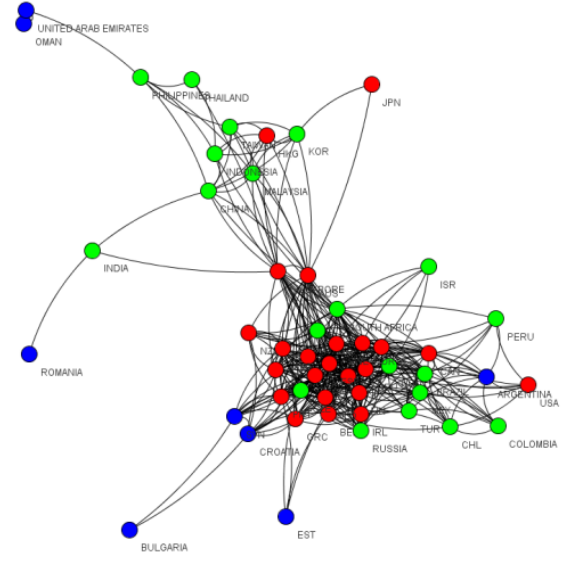

Day 549

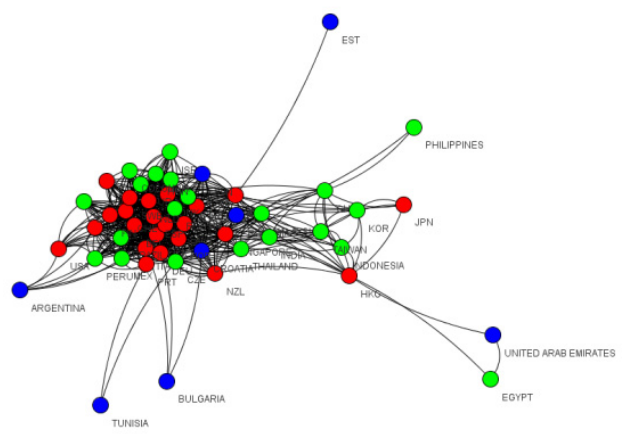

Day 610

Figure 8. Snapshots of global stock market network in Day 549 and Day 610, during a stabilized period. Developed markets are marked as red, emerging markets green and frontier markets blue. Network edges with weight less than 0.5 are eliminated as well as nodes with no edges with weight no less than 0.5 .

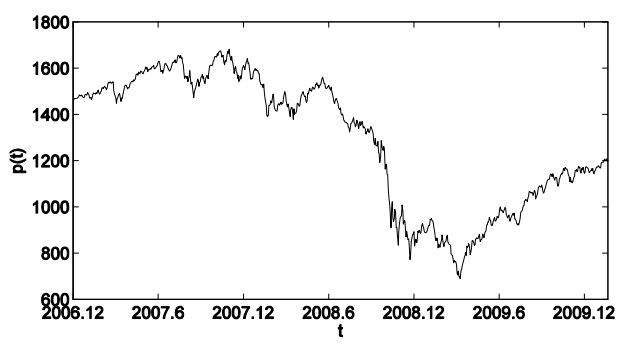

(a)

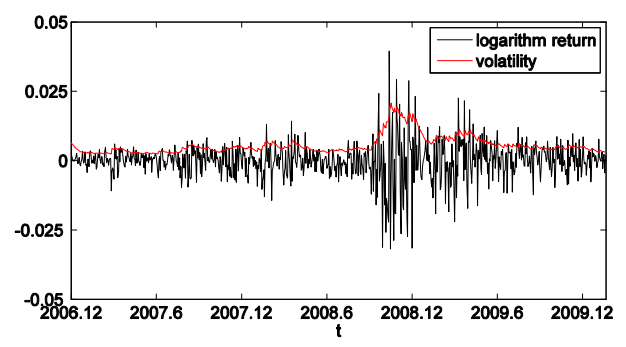

(b)

Figure 9. (a) Daily closing value of World Index. (b) Return and volatility of World Index. 


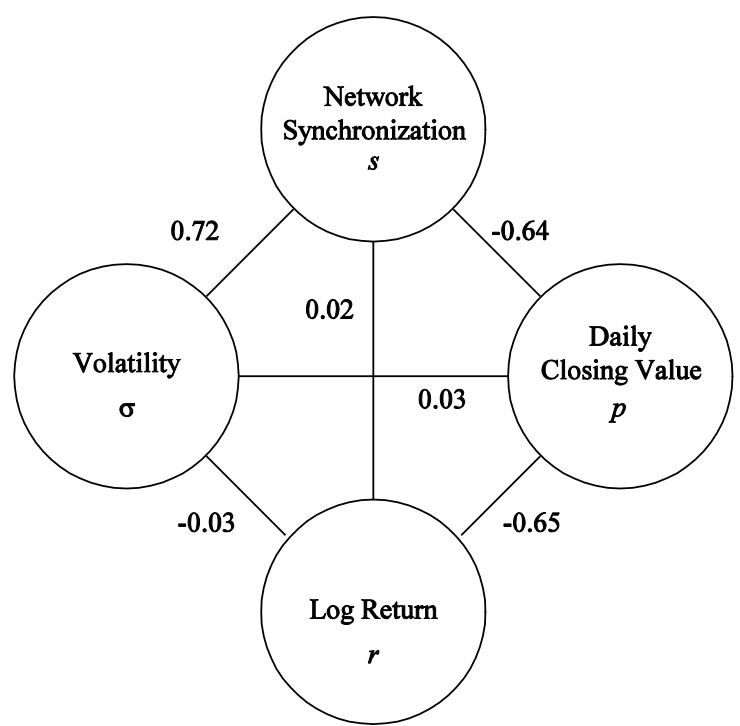

Figure 10. A graphical representation of correlations among network synchronization $s$, World Index's daily closing value $p$, logarithm return $\mathrm{r}$ and volatility $\sigma$. 